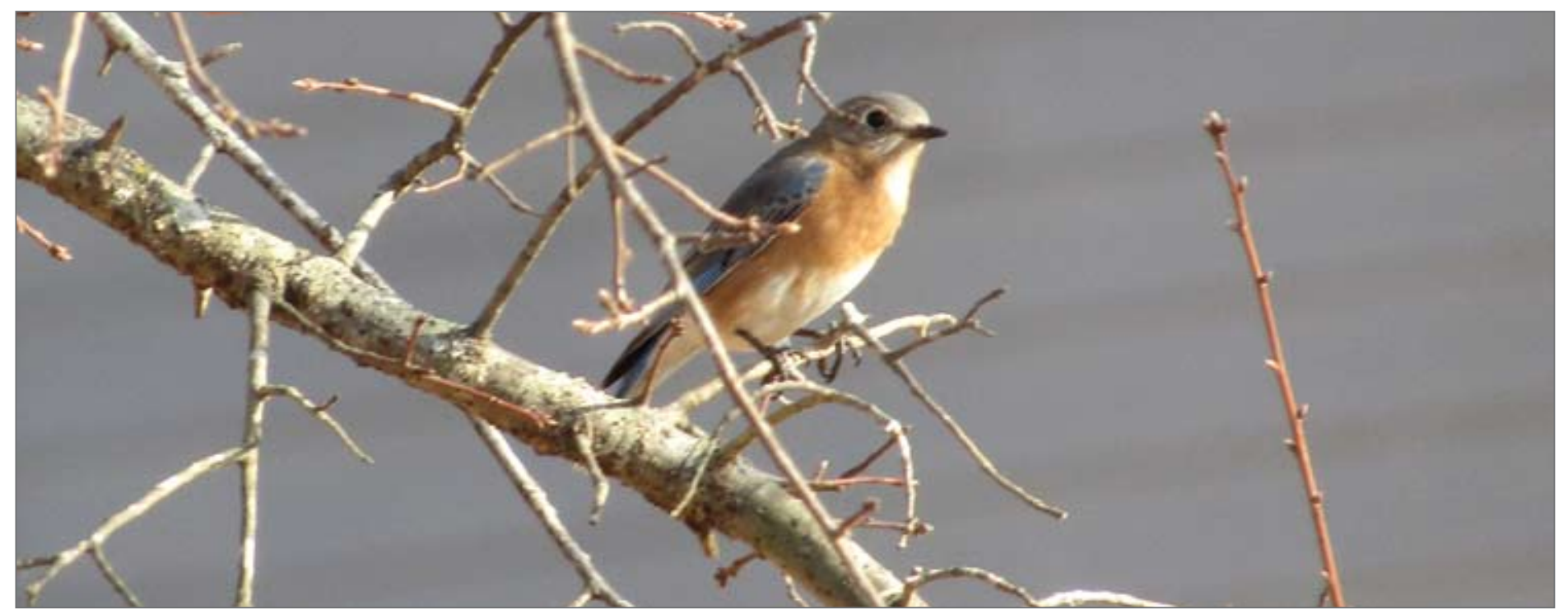

\title{
FRIENDS OF THE BLUEBIRDS STILL GOING STRONG IN MANITOBA
}

Donna Firby Gamache

Box 453

MacGregor, MB ROH ORO

(204) 685-2574

lucgam@mymts.net

Two years ago, 'Friends of the Bluebirds', an affiliate of the North American Bluebird Society (NABS), passed an important milestone. Based in Brandon, Manitoba, 'Friends' celebrated its 40th anniversary since its formation in 1976 , with the aim of promoting recovery of the province's bluebird population.

Friends of the Bluebirds is the legacy of John and Nora Lane of Brandon who began to notice a sharp decline in bluebird numbers, as early as the 1950s. Both species were decreasing - the Mountain Bluebird (Sialia currucoides), a skyblue species found mainly in the western part of Manitoba, as well as in Saskatchewan and Alberta; and the Eastern Bluebird (Sialia sialis), a slightly darker bluebird with a reddish-brown chest, found in south-central and eastern sections of Manitoba, as well as in more easterly provinces. In the past, both species usually built nests in cavities hollowed out by woodpeckers and squirrels, or in decaying dead trees, but these were in ever-shorter supply as woodlands were converted into croplands. Competition from House Sparrows and European Starlings was another problem.

By 1959, John Lane realized that the decline was serious; his records showed that he had seen fewer bluebirds each year. One solution, he believed, was to provide nesting boxes, so he and Nora began to put out lines of bluebird houses on fence posts along rural roads. They also organized the Brandon Junior Bird Club, for youth eight to 18 . Over the next 15 years this group built and set out nearly 5,000 boxes covering much of south-western Manitoba, and as far west as Broadview, Saskatchewan.

John Lane died in 1975, but the following year some of his supporters established Friends of the Bluebirds to carry on his work. Today the group is still going strong. An all-volunteer association, it now has nearly 100 active or supporting members who build and set out boxes across southern Manitoba. They hold two meetings a year, in spring and fall, but most of their work is directed to building, maintaining and monitoring nest boxes. There are no definite requirements or commitments, and no membership fees, although many members also join the North American Bluebird Society (NABS).

Members are encouraged to monitor nests several times each summer, every two weeks if possible, to determine how many eggs are laid and how many young are fledged. In fall, nest boxes need to be cleaned out, with some preferring to leave them open over winter and then reclosing them in early spring.

Statistics from 2015 show 45 individuals or teams sent in reports from about 50 lines, with a total of 1,561 boxes reported. However, since some members do not regularly monitor or report their numbers, it is estimated there may actually be up to 2,500 nest boxes being maintained. Some look after only a 


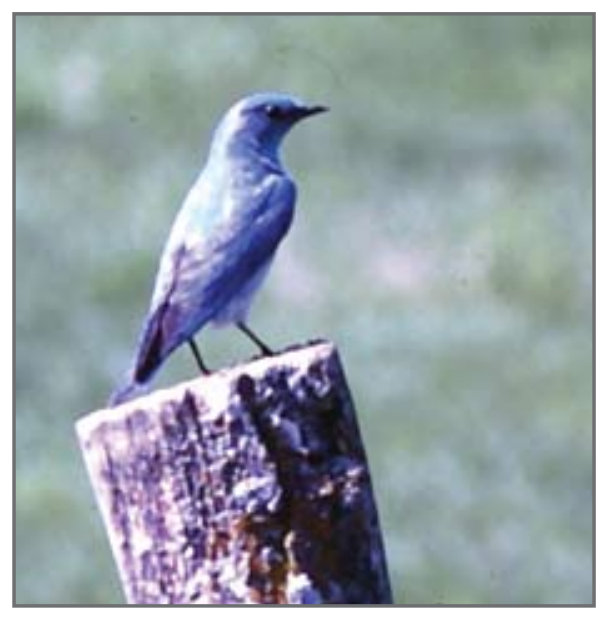

Male Mountain Bluebird. Photo credit: Luc and Donna Gamache

few boxes; others have up to 100 or more! A couple of members are also involved in banding bluebirds.

Over the years, members learned that bluebird lines near pastureland usually do better than those beside crops, due to better habitat. A few trees can help provide perching spots. It is also better to have boxes at least $1 / 2 \mathrm{~km}$ from barns or granaries to discourage House Sparrows. To avoid House Wrens, which also may take over bluebird nests or destroy eggs and fledglings, don't place boxes too close to trees and shrubs. For Mountain Bluebirds, the usual recommended size for nest boxes is 5 " by 5 " with an entrance hole of $19 / 16$ ", but for Eastern Bluebirds the box can be smaller, often 4 " by 4 " with an entrance hole of $11 / 2$ ". Some of our members comment that Eastern Bluebirds often choose the smaller boxes first. The smaller ones are also less attractive to House Sparrows and Tree Swallows (the swallows are welcome, but this is a bluebird organization first and foremost.) For either bluebird species, recommended wall thickness is a minimum of 3/4" (NABS suggests 7/8") because thicker walls provide better insulation against cold or heat. If both bluebird species are present, make sure there are at least some of the larger sized boxes.
One side effect of all the bluebird houses is an increase in the number of Tree Swallows (Tachycineta bicolor) using nesting boxes - an additional benefit, since they are also on the decline in eastern North America. To prevent them from disturbing bluebird nests, many birders place two houses close together; swallows can use one and leave the other for bluebirds. Most members also keep track of swallow eggs and fledgling numbers.

Another interesting development over the years is the gradual spread westward of Eastern Bluebirds. It seems that they are pushing most of the Mountain Bluebirds to the farthest west part of Manitoba. Recent Friends' statistics show some Eastern Bluebirds as far as the Saskatchewan border. Birders in the eastern part of Saskatchewan have noticed Eastern Bluebirds nesting there, too.

Very rarely the two species have been known to inter-breed and produce hybrid fledglings. Friends' statistics show a few such nests in 2015 and 2016, with at least two of these producing fledglings. In 2015, there were six nests of the two mixed species - three of these were one on top of the other by the same pair (male Mountain Bluebird, female Eastern Bluebird) and none were successful. Another nest (male Mountain Bluebird, female Eastern Bluebird) produced three fledglings, and the remaining two nests were found but we have no additional information on these. In 2016, one hybrid nest was found with five eggs, two of which fledged. See http:// www.mbbluebirds.org/?page_id=227 for these statistics.

I find it surprising, when reading the journal published by the North American Bluebird Society, that no affiliate group is listed for Saskatchewan. There are many Bluebird trail operators in Saskatchewan, but no formal Bluebird Society. However, I found information on the 'Bittner box' - a somewhat different type of bluebird nesting box which was developed by Ron Bittner of Abernethy, Saskatchewan. Those interested in trying this box should check out http://www.virtualsk.com/current_ issue/better_birdhouse.html.

If someone is interested in joining the Manitoba 'Friends', they are more than welcome. Attendance at the twice yearly meetings in Brandon is not required - just a desire to help out these beautiful species. Volunteers are always needed to take over existing lines or establish new ones. Even if you don't want to monitor the nests, but do want to help these birds, consider putting out some nest boxes. If you need information on building nest boxes, check their website at: www.mbbluebirds.org.

If someone is interested in starting up a Saskatchewan group, information can be obtained from the Brandon website above, or from the NABS website at www.nabluebirdsociety.org

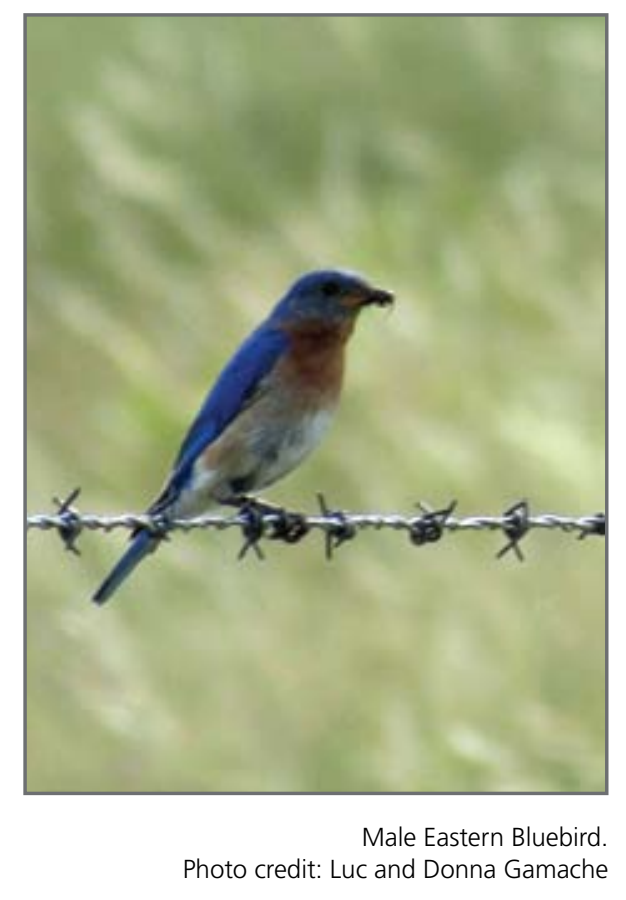

